\title{
Up-to-Date Clinical and Biochemical Workup of the Child and the Adolescent with a Suspected Disorder of Sex Development
}

\author{
Romina P. Grinspon ${ }^{\mathrm{a}}$ Sebastián Castro ${ }^{\mathrm{a}}$ Rodolfo A. Rey ${ }^{\mathrm{a}, \mathrm{b}}$ \\ aCentro de Investigaciones Endocrinológicas "Dr. César Bergadá" (CEDIE), CONICET - FEI - División \\ de Endocrinología, Hospital de Niños Ricardo Gutiérrez, Buenos Aires, Buenos Aires, Argentina; \\ bUniversidad de Buenos Aires, Facultad de Medicina, Departamento de Histología, Embriología, \\ Biología Celular y Genética, Buenos Aires, Argentina
}

\section{Keywords}

Disorders of sex development · Fallopian tubes .

Ovary · Hypogonadism · Persistent Müllerian duct

syndrome $\cdot$ Sertoli cell $\cdot$ Testis $\cdot$ Uterus

\section{Abstract}

Background: The suspicion of a disorder of sex development (DSD) often arises at birth, when the newborn presents with ambiguous genitalia, or even during prenatal ultrasound assessments. Less frequently, the aspect of the external genitalia is typically female or male, and the diagnosis of DSD may be delayed until a karyotype is performed for another health issue, or until pubertal age when a girl presents with absence of thelarche and/or menarche or a boy consults for gynaecomastia and/or small testes. Summary: In this review, we provide a practical, updated approach to clinical and hormonal laboratory workup of the newborn, the child, and the adolescent with a suspected DSD. We focus on how to specifically address the diagnostic approach according to the age and presentation. Key Message: We particularly highlight the importance of a detailed anatomic description of the external and internal genitalia, adequate imaging studies or surgical exploration, the assessment of reproductive hormone levels - especially testosterone, antiMüllerian hormone, 17-hydroxyprogesterone, and gonadotropins - and karyotyping.

(c) 2021 S. Karger AG, Basel

\section{Introduction}

Disorders of sex development (DSDs) result from anomalies in the sexual differentiation of the gonads and/ or the genitalia, wherein there is a discordance between the chromosomal sex, the gonadal structure, and the anatomy of the internal and/or external genitalia. In most cases, the external genitalia are sexually ambiguous. The diagnosis of DSD is suspected at birth or on ultrasound evaluations during pregnancy, when ambiguous genitalia are seen. Less commonly, the appearance of the external genitalia is typically female or male, and the diagnosis may be delayed until the age of puberty. In this review, we will provide an up-to-date and practical approach to the clinical and hormonal laboratory workup of the child and the adolescent with suspected DSD. The advent of high throughput genetic/genomic techniques challenges the need for a comprehensive understanding of the underly-

karger@karger.com www.karger.com/hrp (c) 2021 S. Karger AG, Basel

Karger!
Correspondence to:

Rodolfo A. Rey, rodolforey@ cedie.org.ar 
ing pathophysiology before performing genetic testing in patients with DSD. However, specialists agree on the importance of deep phenotyping as a prerequisite for optimizing the interpretation and outcomes of genomic analysis [1-4]. We will focus on how to specifically address the diagnostic approach according to the age and phenotype, both anatomical and hormonal. The genetic diagnosis of DSD is addressed by another article in this issue. Since the understanding of the mechanisms involved in normal foetal sex differentiation and those involved in the physiology of the reproductive axis after birth is extremely helpful for the choice and interpretation of the assessments used during the clinical and laboratory workup of the patient with a suspicion of DSD, we will start by briefly reviewing the normal process of sex differentiation during prenatal life and the physiology of the postnatal hypothalamic-pituitary-gonadal axis.

\section{Developmental Physiology of the Reproductive System}

\section{Foetal Sex Differentiation}

The chromosomal sex is established at fertilization. However, during approximately 6 weeks, 46,XX and $46, \mathrm{XY}$ embryos are phenotypically identical: the gonadal ridges are sexually undifferentiated, and there are 2 sets of internal ducts: the Wolffian and the Müllerian ducts. Also, the urogenital sinus and the primordia of the external genitalia are undifferentiated; the latter are formed by the genital tubercle, the urogenital folds, and the labioscrotal swellings [5].

The balance between pro-testicular and pro-ovarian gene expression is disrupted by the onset of the expression of the SRY gene, present on the Y chromosome, which triggers the predominance of the testicular gene pathway in the hitherto undifferentiated gonadal ridge [6, 7]. Testicular differentiation is characterized by the formation of the seminiferous cords, containing Sertoli and germ cells, surrounded by the interstitial tissue where lie the Leydig cells. Upon differentiation, Sertoli secrete antiMüllerian hormone (AMH) that provokes the regression of the Müllerian ducts upon binding to its type II receptor [8]. Under the stimulus of placental human chorionic gonadotropin (hCG), Leydig cells produce testosterone, which induces the differentiation of Wolffian ducts into the epididymides, vasa deferentia, and seminal vesicles [9]. In distant organs, testosterone is transformed into the more potent androgen dihydrotestosterone (DHT) by the enzyme $5 a$-reductase type 2 or by the more recently elu-

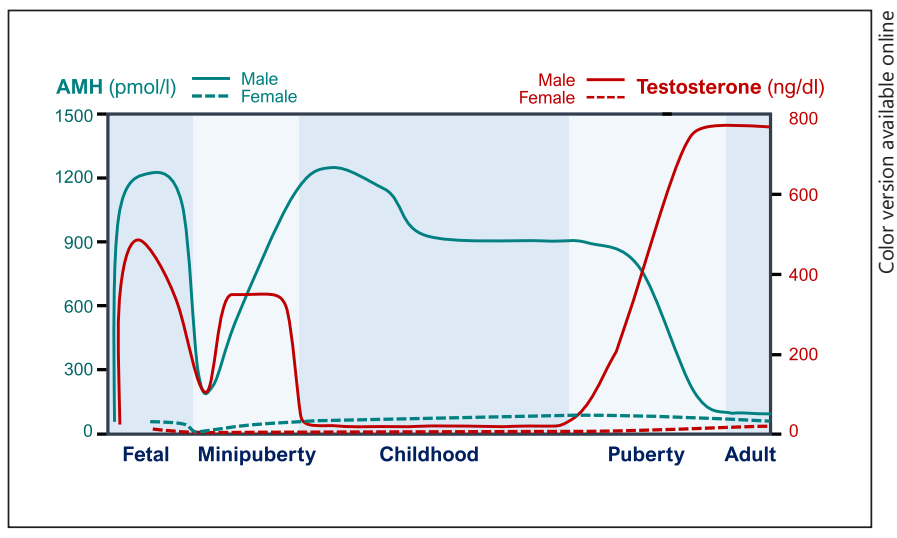

Fig. 1. Schematic of serum levels of testosterone and AMH in the normal male and female during foetal and postnatal development. Lines represent mean serum levels, according to references $[15,17$, $64,65]$. AMH, anti-Müllerian hormone.

cidated enzymatic cascade known as the "backdoor pathway" [10]. Thus, through DHT binding to the androgen receptor, the urogenital sinus virilizes and gives rise to the prostate and part of the male urethra [11], the genital tubercle forms the corpora cavernosa, corpus spongiosum, and glans of the penis; the urogenital folds fuse to close the penile urethra with its orifice at the tip of the glans; and the labioscrotal swellings fuse to give rise to the scrotum [12]. Foetal virilization is completed by the end of the first trimester, with no involvement of pituitary gonadotropins. During the second and third trimesters of gestation, androgen secretion - driven by foetal pituitary LH - increases the trophism of the penis and scrotum and drives testicular descent together with insulin-like factor 3 [13]. In the absence of testicular hormones, irrespective of the existence of ovarian tissue, Wolffian ducts regress; Müllerian ducts give rise to the Fallopian tubes, the uterus, and the upper part of the vagina [14]; the urogenital sinus follows the female pathway giving rise to the female urethra and the lower part of the vagina with separate endings; the genital tubercle forms the clitoris; and the urogenital folds and the labioscrotal swellings, respectively, differentiate into the labia minora and labia majora [12].

\section{Postnatal Development of the Reproductive Axis}

Gonadotropins and gonadal sex steroids are very low in the first days after birth. AMH and inhibin B are also low, but there is a clear sexual dimorphism, with distinctively higher levels in males (Fig. 1) [15]. All hormone levels increase from the end of the first week onwards. In male individuals, $\mathrm{LH}$ is usually higher than FSH; gonad- 
otropins and testosterone remain high during 3-6 months [16] and then the axis becomes relatively quiescent until the onset of puberty. However, AMH and inhibin $B$ show high levels during the whole prepubertal period [17]. At the age of puberty, gonadotropins increase, together with inhibin B and testosterone, while $\mathrm{AMH}$ decreases in response to testosterone action [18]. Inhibin B is the main feedback regulator of FSH, whereas testosterone exerts a negative feedback on LH. Testes show a modest increase in size (up to 5-6 mL) due to Sertoli cell proliferation under FSH action at the beginning of puberty; at this stage (Tanner stage 2), intratesticular testosterone increases, but plasma testosterone levels remain undetectable or very low. Subsequently, between Tanner stages 3 and 5, there is a substantial increase in testicular volume (up to $25 \mathrm{~mL}$ ) due to the progression of spermatogenesis [19].

In female individuals, FSH is higher than LH during the postnatal activation period [15], which lasts for approximately 2 years [20]. Gonadotropins and oestradiol increase at pubertal age, with the typically cyclic pattern established towards menarche. Oestradiol and inhibins induce a negative feedback on the gonadotroph. Oestrogens induce breast development, and menarche occurs approximately $2-3$ years later.

In both sexes, pubic hair development depends on the action of androgens that can be of gonadal or adrenal origin. In boys, testicular androgens are more abundant and potent than adrenal ones.

\section{Pathogenesis of DSD}

The pathogenesis of DSD varies according to the step of foetal development that is affected. In the first 6 weeks of gestation, before the gonads differentiate, malformations may occur in the anlagen of the internal genitalia (Müllerian or Wolffian ducts), the urogenital sinus (cloacal malformations), or the primordia of the external genitalia. In these malformative, non-endocrine DSD, gonadal function is usually preserved, and the anatomical defects cannot be explained by hormonal defects [21].

Virilization of 46,XX newborns indicates the existence of an androgen excess, which is isolated in the case of congenital adrenal hyperplasia (CAH), placental aromatase deficiency or maternal hyperandrogenic states, or associated with an excess of $\mathrm{AMH}$ in the case of ovotesticular or testicular DSD. In the first case, the newborn will have ambiguous or male external genitalia with preserved uterus and Fallopian tubes, whereas in the latter, ambigu-

Clinical and Laboratory Workup in

Disorder of Sex Development ous or discordant external genitalia occur concomitantly with absent or defective Müllerian derivatives [22].

Undervirilization of individuals with a 46,XY karyotype or variants carrying a $Y$ chromosome reveals an insufficient androgen production or action. This can be due to a foetal primary hypogonadism resulting in inadequate secretion of both testosterone and $\mathrm{AMH}$, where ambiguous or female genitalia are associated with the presence of Müllerian remnants, or in isolated androgen synthesis disorders, where Müllerian derivatives are absent. Various forms of gonadal dysgenesis underlie the first situation, whereas specific defects in the LH/CG receptor or the proteins or enzymes involved in gonadal steroidogenesis are the aetiologies of the latter [5]. Alternatively, testicular hormone production may be normal, yet in the context of androgen insensitivity due to androgen receptor defects [23]. Finally, a rare form of DSD is the persistence of the uterus in an otherwise normally virilized boy, due to specific defects in AMH or its receptor [24].

A detailed evaluation and a precise description of the genital phenotype at birth are most relevant. The genital examination should allow a comprehensive description of the size of the phallus and location of the urethral meatus, the presence and location of the gonads, and the degree of fusion of the labioscrotal folds and the anogenital distance. In 1954, the Prader score was developed to characterize children with CAH [25]. In 2000, the external masculinization score (EMS) was introduced to describe the genital appearance in boys [26]. More recently, the external genitalia score (EGS) was developed by the European Cooperation in Science and Technology (COST) Action BM1303 and validated as a reliable tool allowing an objective description of typical and ambiguous external genitalia in newborns (Table 1) [27].

In the following sections, we will address the anatomical and hormonal laboratory features that may help in the diagnostic process. The advent of high-throughput genetic/genomic techniques challenges the need for a comprehensive understanding of the underlying pathophysiology before performing genetic testing in patients with DSD. However, specialists agree on the importance of deep phenotyping as a prerequisite for optimizing the interpretation and outcomes of genomic analysis.

\section{Workup of the Newborn with a Suspected DSD}

A suspicion of DSD may occur before birth, when routine ultrasonography detects atypical genitalia or typical genitalia that are discordant with the foetal chromosomal 
Table 1. External genitalia score

\begin{tabular}{|c|c|c|c|c|c|}
\hline $\begin{array}{l}\text { Phallus length, } \\
\mathrm{mm}\end{array}$ & Urethral meatus position & Labioscrotal folds & Left gonad & Right gonad & EGS \\
\hline$>31$ & Tip of penis & \multirow[t]{3}{*}{ Fused completely } & & & 3.0 \\
\hline $26-30$ & Coronal/glandular & & & & 2.5 \\
\hline & Along the phallus & & & & 2.0 \\
\hline $21-25$ & At the phallus base & \multirow{3}{*}{ Posterior fusion } & Labioscrotal & Labioscrotal & 1.5 \\
\hline \multirow[t]{2}{*}{$10-20$} & \multirow[t]{2}{*}{ Labioscrotal } & & Inguino-scrotal & Inguino-scrotal & 1.0 \\
\hline & & & Inguinal & Inguinal & 0.5 \\
\hline$<10$ & Perineal & Completely unfused & Non-palpable & Non-palpable & 0.0 \\
\hline
\end{tabular}

EGS, external genitalia score. Data taken from van der Straaten et al. [27].

sex in a karyotype often performed for maternal age or for a reason not associated with foetal sex, for example, malformations and growth restriction. Alternatively, DSD is suspected at birth most frequently when the newborn presents with ambiguous genitalia.

\section{Ambiguous Genitalia Detected during Pregnancy or at Birth}

The birth of a baby with ambiguous genitalia (typically with an EGS between 1.5 and 10) represents a challenge for the family and for the healthcare team. There is urgency to rule out $\mathrm{CAH}$, owing to its relative frequency and life-threatening potential, especially in the absence of palpable gonads.

46 ,XX DSD in the newborn determination of 17-hydroxyprogesterone (17-OHP) and a karyotype may give a rapid clue (Fig. 2). An elevated level of 17-OHP leads to the diagnosis of CAH. The girl presents with virilized external genitalia but a normal uterus, and the hormonal laboratory shows elevated testosterone but AMH and gonadotropins in the normal female range. In the rare cases where 17-OHP is within the normal range in a 46,XX newborn with elevated testosterone, together with $\mathrm{AMH}$ in the female range and the presence of a normal uterus, a deficiency of aromatase is suspected when gonadotropins are elevated [28]. Conversely, when gonadotropin levels are low or suppressed, a virilizing tumour or the use of androgenic drugs in the mother should be suspected. Maternal virilization during pregnancy occurs in the latter 3 conditions; signs of androgenization are more evident and persist after birth in the newborn with aromatase deficiency, while they regress in the mother. On the contrary, virilization is more marked in the mother and persists in the case of an androgen-secreting tumour or androgenic drug use, while the newborn is relatively pro- tected and the subtle signs of virilization wane progressively $[29,30]$. In the $46, \mathrm{XX}$ newborn with testosterone and $\mathrm{AMH}$ levels above the female range, usually associated with poor or complete absence of Müllerian structures, the existence of testicular tissue is suspected, leading to the diagnosis of testicular or ovotesticular DSD. The definitive diagnosis is based on the histology of the gonads, and the establishment of the genetic aetiology may be simple when $S R Y$ sequences are detected but may be challenging in their absence [31].

$46, \mathrm{XY}$ DSD in the 46,XY newborn represents a major challenge to deal with [32]. Deep phenotyping in the search for non-genital dysmorphism together with microarrays and next generation sequence technologies has visibly increased the aetiological diagnosis rate; nonetheless, more than $50 \%$ of the cases remain as "idiopathic" $[1,4]$. The determination of the 2 "foetal male" hormones can be very informative for a first classification (Fig. 2). Testosterone and AMH below the male range for age indicate the existence of an early foetal-onset hypogonadism affecting both Leydig and Sertoli cells, typical of gonadal dysgenesis $[5,33]$. In this case, gonadotropin levels are elevated, especially FSH, and Müllerian derivatives are present. Imaging (ultrasound) and urethro-cystoscopy are necessary to assess the anatomical features, and gonadal histology is usually required later in life to evaluate tumour risk.

Undervirilization of the external genitalia may also be due to a dissociated foetal-onset hypogonadism, where only Leydig cell androgen production is impaired. These forms of DSD are characterized by low testosterone but normal male AMH, and the absence of Müllerian remnants $[5,34]$. The accurate assessment of steroidogenesis can only be made using mass spectrometry following either gas or liquid chromatography [35]. Basal levels of the 


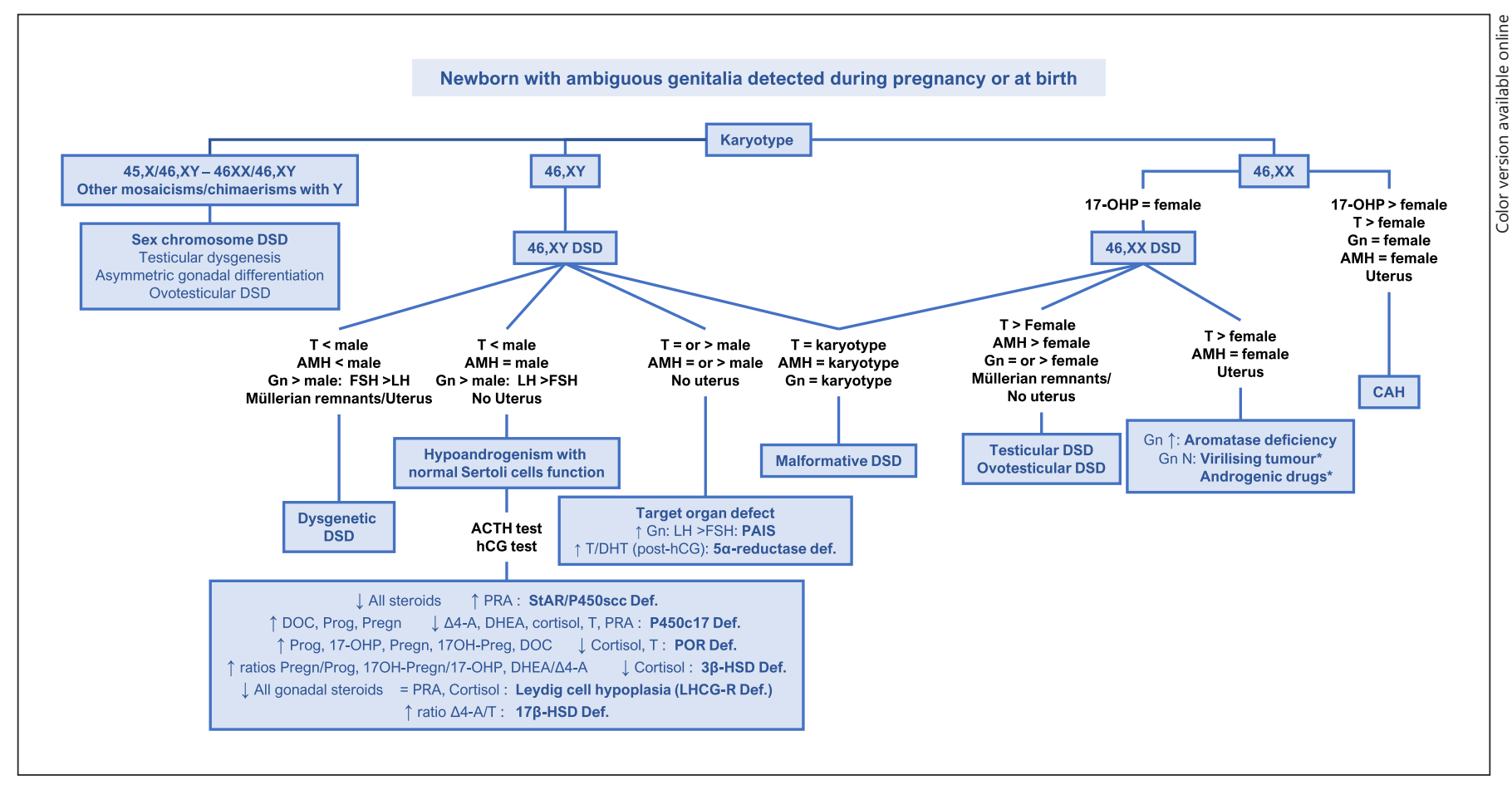

Fig. 2. Diagnostic approach in face of a newborn with ambiguous genitalia detected during pregnancy or at birth. 17-OHP, 17-hydroxyprogesterone; $\Delta 4-\mathrm{A}$, delta- 4 androstenedione; ACTH, adrenocorticotrophin; $\mathrm{AMH}$, anti-Müllerian hormone; $\mathrm{CAH}$, congenital adrenal hyperplasia; Def., deficiency; DHEA, dehydroepiandrosterone;DHT, dihydrotestosterone; DOC, deoxycorticosterone; $\mathrm{DSD}$, disorder of sex development; Gn, gonadotropins; hCG, hu- man chorionic gonadotropin; HSD, hydroxysteroid dehydrogenase; LHCG-R, receptor for LH and hCG; N, normal; PAIS, Partial androgen insensitivity syndrome; PRA, plasma renin activity; Pregn., pregnenolone; Prog., progesterone; StAR, steroidogenic acute regulatory protein; $\mathrm{T}$, testosterone; $\uparrow$, increased; $\downarrow$, decreased; $>$, = or $<$ : above, within or below normal range for age; ${ }^{*}$, maternal virilizing tumour or androgenic drug use. various steroids may not be sufficiently informative, but ACTH and hCG stimulation tests guide the diagnosis (Fig. 2) [33]: an insufficient response of all testicular steroids to hCG associated with a normal response to ACTH and normal plasma renin activity (PRA) points to a Leydig cell hypoplasia [36]. If only testosterone is low, with a $\Delta 4$-androstenedione $(\Delta 4-\mathrm{A}) /$ testosterone ratio $>1$, a $17 \beta$-hydroxysteroid dehydrogenase type 3 deficiency is suspected $[37,38]$. These 2 situations do not raise concern for potential adrenal failure. Conversely, if all steroids are low after ACTH stimulation, and PRA is elevated, defects in StAR or P450scc (CYP11A1) are likely. Elevated pregnenolone, progesterone, deoxycorticosterone (DOC), $18 \mathrm{OH}-\mathrm{DOC}$, corticosterone, and $18 \mathrm{OH}$-corticosterone, with low $\triangle 4$-A, DHEA, testosterone, and cortisol point to P450c17 deficiency, typically showing decreased PRA and hypokalaemia $[38,39]$. Combined mild elevation of pregnenolone, progesterone, 17-hydroxypregnenolone, 17-OHP, and DOC, with variable cortisol response to ACTH is characteristic of P450 oxidoreductase (POR) deficiency. Maternal virilization reflects aromatase impairment, and skeletal malformations typical of the Antley-Bixler syndrome in the child are suggestive of POR deficiency $[38,40]$. When the ratio between $\Delta 5$ (pregnenolone, 17-hydroxypregnenolone, DHEA, androstenedi$\mathrm{ol}$ ) and $\Delta 4$ steroids (progesterone, $17-\mathrm{OHP}, \Delta 4-\mathrm{A}$, testosterone) is elevated, and particularly 17 -hydroxypregnenolone/cortisol after ACTH stimulation, a deficiency in $3 \beta$-hydroxysteroid dehydrogenase type 2 is the most likely diagnosis $[41,42]$. All conditions where steroid response to ACTH is impaired usually present with basal elevation of ACTH levels and need glucocorticoid, and sometimes mineralocorticoid, replacement due to adrenal insufficiency associated with these infrequent forms of CAH [38]. Imaging and urethro-cystoscopy establish the anatomical features, but gonadal histology is not required since tumour risk is not increased in these cases.

Both androgen and AMH levels may be within the male range, or even higher, in newborns with external ambiguous genitalia and no uterus. The differential diag- 
nosis between partial androgen insensitivity syndrome (PAIS) and a deficiency in DHT synthesis may be challenging with the usually available laboratory tools (Fig. 2). A predominant elevation of LH is more frequently associated with PAIS [43], whereas an elevation of the T/ DHT ratio above 10 after hCG stimulation points to DHT deficiency associated with 5a-reductase type 2 deficiency $[36,44]$. However, since the expression of $S R$ $D 5 A 2$, encoding $5 \alpha$-reductase type 2 , is under androgen control [45], DHT production may be impaired also in patients with PAIS, resulting in an elevated T/DHT ratio $[46,47]$. Gas chromatography-mass spectrometry findings of high tetrahydro-cortisol/allo-tetrahydro-cortisol and etiocholanolone/androsterone urine ratios have higher specificity $[35,48]$, but urine testing may be challenging in newborns. DHT insufficiency may exist due to defects in the alternative "backdoor" pathway not involving testosterone [49]. Usual steroid determinations are unable to detect this infrequent disorder, which may be confused with defects in P450c17, and urinary steroid metabolome analysis may be necessary for a differential diagnosis [35]. Ultrasonography and urethro-cystography are performed for the assessment of the anatomical defects, but histological analysis is not necessary. Finally, patients with 46,XY DSD and testicular hormone levels within the normal male range may reflect a non-endocrine aetiology (Fig. 2), where the most likely pathogenesis is the failure of hormone-unrelated morphogenetic factors involved in the development of the external genitalia, resulting in endocrine-independent genital malformations [21].

\section{Sex Chromosome DSD}

The detection of sex chromosome abnormalities facilitates the understanding of the underlying pathogenesis in newborns with ambiguous genitalia. The existence of a Y chromosome justifies the development of testicular tissue, whereas its presence as mosaicisms or chimaerisms explains gonadal dysgenesis resulting in insufficient levels of testosterone and AMH to provoke complete masculinization (Fig. 2). The histological assessment clarifies whether it corresponds to testicular dysgenesis, asymmetric gonadal differentiation (also called mixed gonadal dysgenesis), or ovotesticular DSD. Serum testosterone and AMH levels are usually between the male and female ranges and reflect the amount of functional testicular tissue [50]. Imaging and histologic studies are necessary, as described above for patients with $46, \mathrm{XY}$ dysgenetic DSD.
Discordance between Typical Genitalia and Karyotype during Pregnancy or at Birth

The increasing use of karyotyping during pregnancy has raised the rate of diagnosis of discordances between chromosomal and external genital sex. The confirmation of external genitalia of typical female or male aspect but discordant with the newborn's karyotype prompts the search for DSD (Fig. 3). The coexistence of a 46, XX karyotype with male genitalia and non-papable gonads is indicative of a completely virilized (Prader stage V or EGS 9) patient with CAH. Elevated 17-OHP, male-range testosterone, and female-range $\mathrm{AMH}$, with normal serum gonadotropins and the existence of a uterus in ultrasound assessment are highly suggestive of 21-hydroxylase (CYP21A2) deficiency. P450c11 (CYP11B1) [51] and POR [52] deficiencies can also result in complete virilization. Elevated 11-deoxycortisol and DOC both basally and after ACTH, high basal ACTH, decreased PRA, and hypokalaemia are typical of $\mathrm{P} 450 \mathrm{c} 11 \beta$ deficiency, whereas mixed features of 21-hydroxylase, 17-hydroxylase, and aromatase deficiencies characterize POR defects, as described above $[38,52]$. In contrast, testicular DSD (also known as XX male) is the most likely diagnosis when gonads are present, most frequently in scrotal position (EGS 12 ), and when testosterone, $\mathrm{AMH}$, and gonadotropins are within the normal male range [31].

The newborn girl (EGS 0) with a 46,XY karyotype represents the complete forms of gonadal dysgenesis, hypoandrogenism due to steroidogenic deficiency with normal Sertoli cell function or androgen target organ defects, including complete androgen insensitivity syndrome (CAIS) and DHT deficiency (Fig. 3). Endocrine laboratory features resemble those described for the 46 , XY newborn with ambiguous genitalia, except that testosterone and $\mathrm{AMH}$ are undetectable and gonadotropins are extremely high in the dysgenetic forms [53], and testosterone is undetectable but LH may be normal or only mildly elevated in CAIS [43].

\section{Workup of the Child with a Suspected DSD}

\section{Ambiguous Genitalia or Discordance between}

External Genitalia and Karyotype

The diagnostic approach in front of a child with ambiguous genitalia or with a discordance between external genitalia and karyotype resembles that used for the newborn (see above, and Fig. 2, 3), with slight differences. Basal testosterone measurement may no longer be informative, especially if gonadotropins are within the normal 


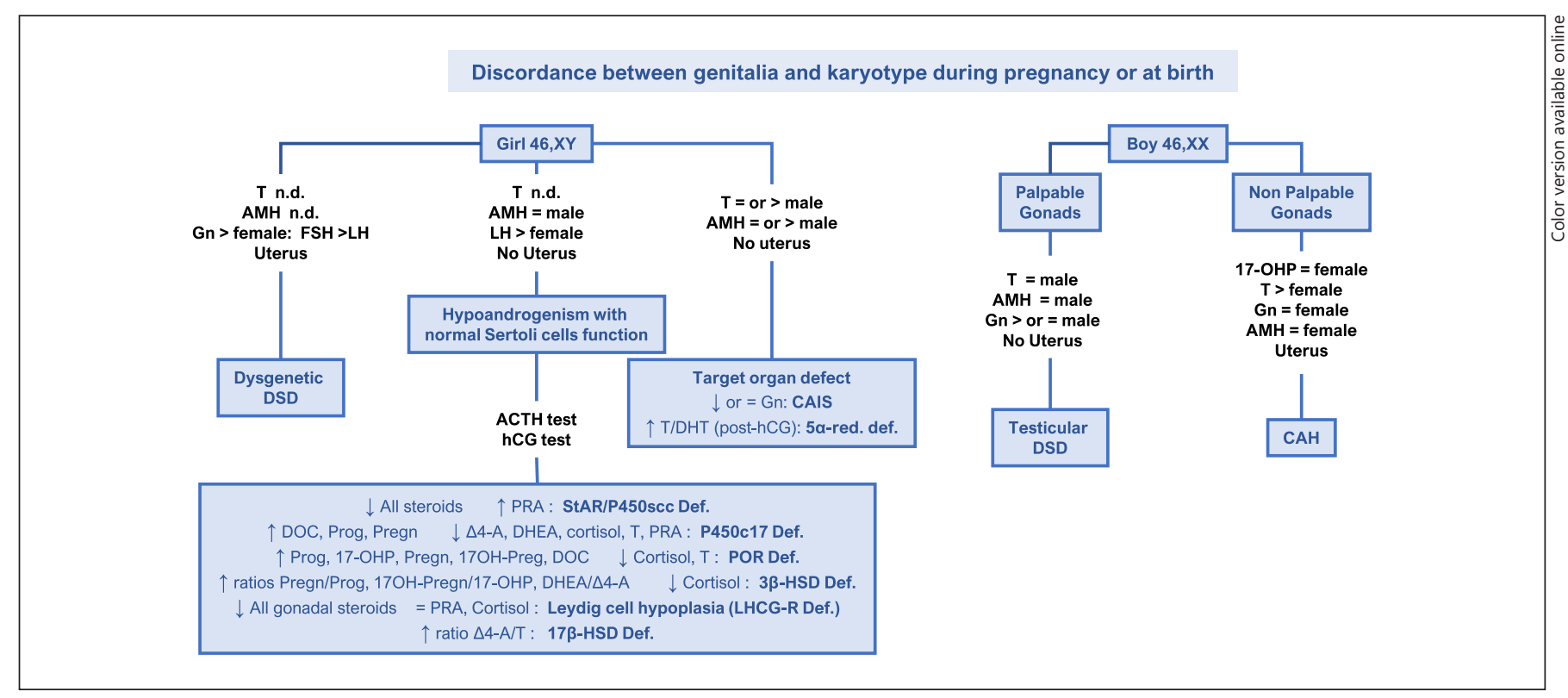

Fig. 3. Diagnostic approach in face of a newborn in whom there is a discordance between genitalia and karyotype discovered during pregnancy or at birth. 17-OHP, 17-hydroxyprogesterone; $\Delta 4-\mathrm{A}$, delta-4 androstenedione; ACTH, adrenocorticotrophin; $\mathrm{AMH}$, anti-Müllerian hormone; $\mathrm{CAH}$, congenital adrenal hyperplasia; CAIS, complete androgen insensitivity syndrome; Def., deficiency; DHEA, dehydroepiandrosterone; DHT, dihydrotestosterone;
DOC, deoxycorticosterone; DSD, disorder of sex development; Gn, gonadotropins; hCG, human chorionic gonadotropin; HSD, hydroxysteroid dehydrogenase; LHCG-R, receptor for LH and hCG; N, normal; PRA, plasma renin activity; Pregn., pregnenolone; Prog., progesterone; StAR, steroidogenic acute regulatory protein; T, testosterone; $\uparrow$, increased; $\downarrow$, decreased; $>$, = or $<$ : above, within or below normal range for age. n.d., nondetectable. range for age. Serum AMH is still useful to search for the existence of testicular tissue [50]. Life-threatening CAH due to salt-wasting is no longer a concern, and only simple virilizing forms should be considered.

In $46, \mathrm{XX}$ patients, the history of neonatal virilization that did not progress or showed some regression is compatible with a maternal source of androgens (virilizing tumour, androgenic drug use) or aromatase deficiency. In patients with a 46,XY karyotype or with sex chromosome abnormalities, serum AMH is informative of the amount of functional testicular tissue and helps distinguish between dysgenetic and non-dysgenetic forms. ACTH and hCG tests are necessary to make a differential diagnosis in the latter, between steroidogenic disorders and androgen insensitivity, since basal testosterone and gonadotropins are normally low and thus uninformative.

\section{Presence of Uterus and Fallopian Tubes in a Boy with Cryptorchidism}

Rarely, the existence of Müllerian derivatives may be discovered during the assessment or surgical treatment of a boy with cryptorchidism and completely virilized external genitalia. This condition, known as the persistent
Müllerian duct syndrome (PMDS), is due to a defect in AMH secretion or in its receptor [24]. In these boys, testosterone and gonadotropin levels are normal according to age, and serum AMH is suggestive of an $A M H$ gene mutation, when very low or undetectable, or of AMH resistance due to pathogenic variants in the AMH receptor type 2, when normal for age (Fig. 4a).

\section{Workup of the Adolescent with a Suspected DSD}

\section{Boys with Small Testes}

In adolescent males with no clearly apparent genital ambiguity, lack of progressive increase of testicular volume and/or breast development may be due to DSD. The karyotype is usually very informative (Fig. 4b). In 47, $\mathrm{XXY}$ and variants, small testes and gynaecomastia is the most frequent clinical presentation [54]; all reproductive hormones are within the normal male range until Tanner stage 3 , the gonadotropins increase and the testicular hormones decline [55]. When the karyotype is $46, \mathrm{XX}$ or $46, \mathrm{XX} / 46, \mathrm{XY}$, ovotesticular or testicular DSD with adequate amount of functional testicular tissue is likely; se- 


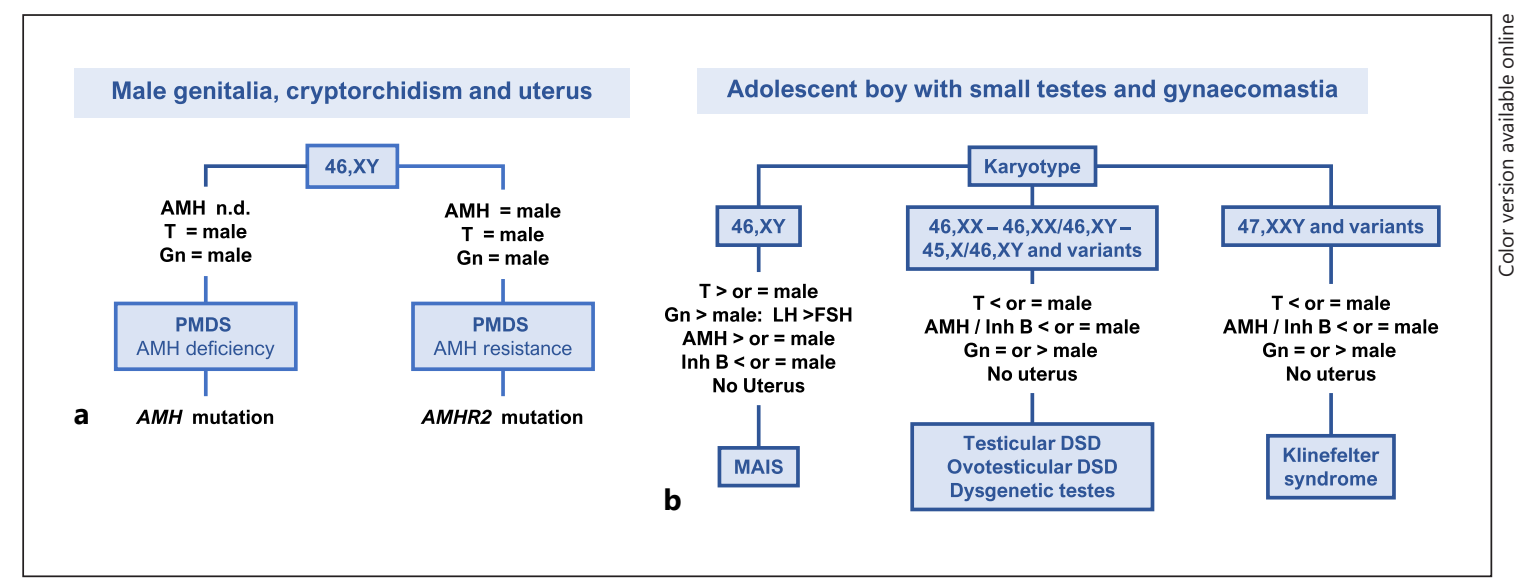

Fig. 4. Possible diagnoses in a boy with cryptorchidism, gynaecomastia and/or small testes. a Boy with cryptorchidism and uterus. b Adolescent with small testes and/or gynaecomastia.AMH, anti-Müllerian hormone; AMHR2, AMH receptor type 2; Gn, gonadotropins; DSD, disorder of sex development; Inh B, inhibin B; N, normal; MAIS, mild androgen insensitivity syndrome; PMDS, persistent Müllerian duct syndrome; T, testosterone; $>$, = or <: above, within or below normal range for age.

rum hormones are very similar to those described for Klinefelter syndrome [50]. Finally, in 46,XY patients with elevated $\mathrm{LH}$, testosterone, and AMH above the male range for age and Tanner stage, and decreased inhibin $\mathrm{B}$, a mild form of androgen sensitivity is suspected.

\section{Girls without Thelarche and/or Menarche}

The absence of pubertal signs should prompt the search for a DSD in a girl > 13 years, even if other diagnoses such as constitutional delay of puberty are more prevalent. The lack of breast development, that is, Tanner stage B1, is clearly indicative of no oestrogen action. The finding of a 45,X karyotype in a girl with more or less anatomical features of Turner syndrome, elevated gonadotropins, and undetectable oestradiol and AMH rapidly establishes the aetiology of primary gonadal insufficiency (hypergonadotrophic hypogonadism) due to complete gonadal dysgenesis (Fig. 5) [56].

Primary ovarian insufficiency may also be the cause of pubertal delay in $46, \mathrm{XX}$ girls, and elevated gonadotropin associated with undetectable oestradiol and AMH are clear biomarkers of congenital ovarian dysgenesis [57] or of congenital ovarian and Müllerian duct agenesis, which can occur in the spectrum of Mayer-Rokitansky-KüsterHauser syndrome [58]. Prepubertal oestradiol and gonadotropin levels, with normal or mildly decreased AMH are suggestive of central (hypogonadotrophic) hypogonadism [59]. A rare disorder, due to $\mathrm{FSH}$ receptor inactivating mutations, may present with prepubertal oestradiol, high FSH, and normal AMH levels [57]. In the 2 latter conditions, $\mathrm{AMH}$ reflects the existence of a conserved ovarian follicle reserve.

When the karyotype is 46,XY (Fig. 5), complete gonadal dysgenesis or absent steroid production due to Leydig cell aplasia in a patient with abdominal testes are the possible causes. Oestradiol is undetectable and gonadotropins are elevated; when $\mathrm{AMH}$ is undetectable and a uterus is present, a dysgenetic DSD is the diagnosis, whereas the absence of the uterus and AMH levels in the male range are indicative of the existence of abdominal testes that do not produce androgens $[5,50]$. Only Leydig cell aplasia, due to completely inactivating mutation of LHCGR, is likely since other steroidogenic defects result in adrenal insufficiency [38] and/or partial virilization $[37,38]$.

The existence of breast development reflects oestrogenic activity (Fig. 5), which occurs in a proportion of patients with Turner syndrome, especially those with sex chromosome mosaicism; serum AMH is commensurate with ovarian follicle reserve [56]. In 46,XX cases, when all reproductive hormones are within the female range, Mayer-Rokitansky-Küster-Hauser syndrome is likely, and imaging is confirmatory of the absence of uterus. When the uterus is present, oestradiol and $\mathrm{AMH}$ are below the female range, gonadotropins are elevated, and partial ovarian dysgenesis is suspected. Conversely, testosterone and AMH levels above the female range with clitoris enlargement and hirsutism point to the existence of some testicular tissue, that is, ovotesticular DSD. Müllerian derivatives are expected to have devel- 


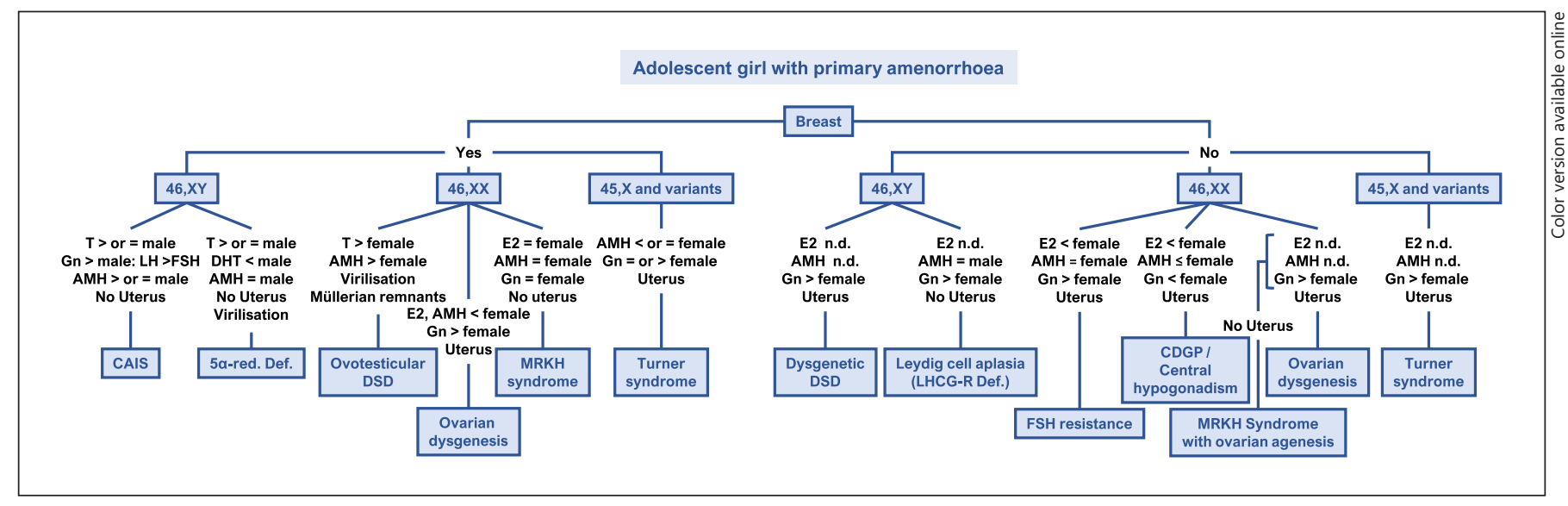

Fig. 5. Diagnostic approach in an adolescent girl with primary amenorrhoea and suspicion of DSD, according to whether there is breast development or not. AMH, anti-Müllerian hormone; Def., deficiency; DHT, dihydrotestosterone; E2, oestradiol; DSD, disorder of sex development; Gn, gonadotropins; LHCG-R, receptor for LH and hCG; MRKH, Mayer-Rokitansky-Küster-Hauser; N, normal; red, reductase; T, testosterone; >, = or <: above, within or below normal range for age. n.d.: non detectable.

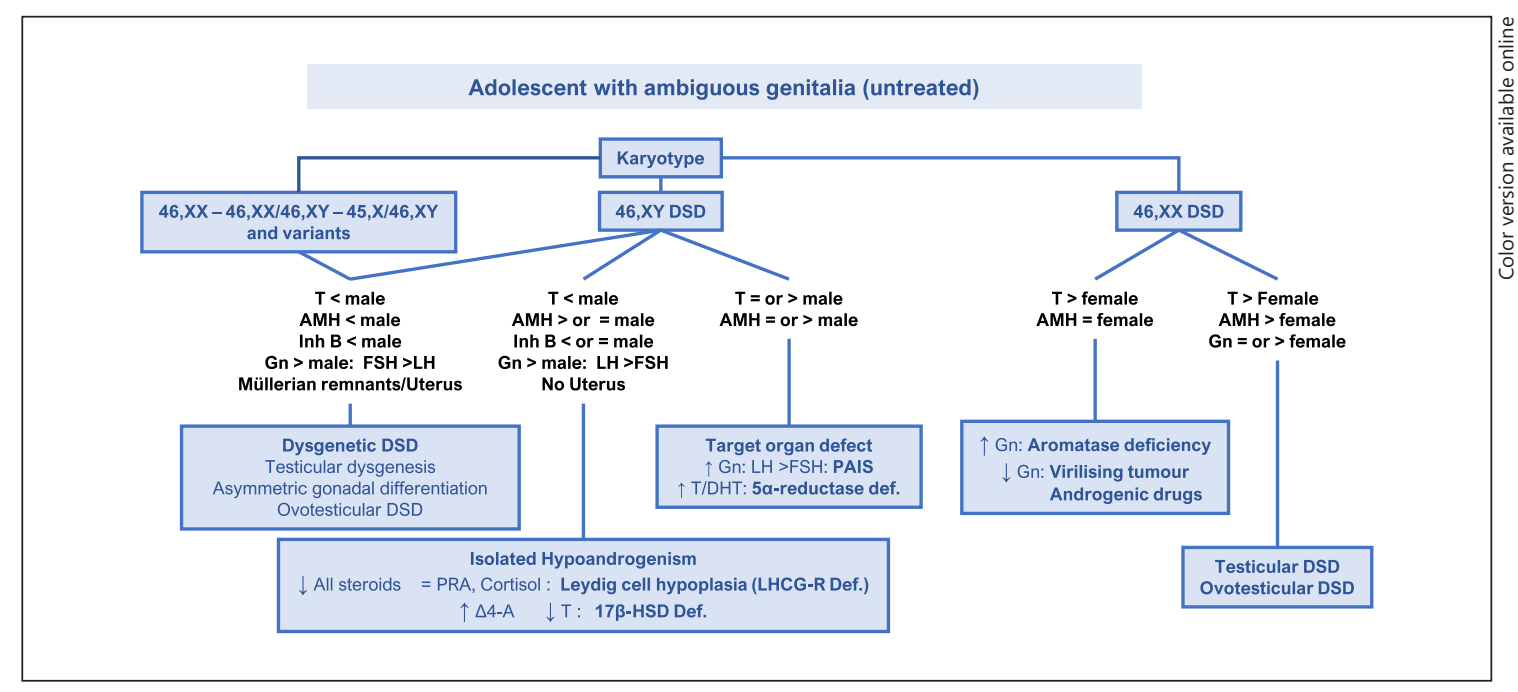

Fig. 6. Diagnostic approach in the face of an untreated adolescent with ambiguous genitalia. $\Delta 4-\mathrm{A}$, delta- 4 androstenedione; $\mathrm{AMH}$, anti-Müllerian hormone; $\mathrm{CAH}$, congenital adrenal hyperplasia; Def., deficiency; DHT, dihydrotestosterone; DOC, deoxycorticosterone; DSD, disorder of sex development; Gn, gonadotropins; hCG, human chorionic gonadotropin; HSD, hydroxysteroid dehydrogenase; LHCG-R, receptor for LH and hCG; N, normal; PRA, plasma renin activity; T, testosterone; $\uparrow$, increased; $\downarrow$, decreased; $>$, = or <: above, within or below normal range for age.

oped since the amount of functional testicular tissue is predicted to be scarce. Finally, in 46,XY girls with breast development, amenorrhoea is due to the absence of uterus. Testosterone and $\mathrm{AMH}$ are in the male range, reflecting the existence of functional testes: while $\mathrm{AMH}$ is very high in CAIS, reflecting the lack of androgen action and the oestrogenic effect $[50,60,61]$, it is within the lower pubertal range in patients with severe $5 a$-reductase deficiency [62].

\section{Patients with Ambiguous Genitalia}

Untreated individuals with DSD rarely present at puberty; however, this may occur in isolated communities, far away from big cities with specialized healthcare cen- 
tres. Considerations are similar to those described for newborns with ambiguous genitalia, except that those conditions associated with adrenal insufficiency are highly unlikely to go undiagnosed until pubertal age (Fig. 6).

\section{Counselling Parents of a Child with DSD}

Given its increasing complexity, an optimal care for patients with DSD requires a proficient multidisciplinary team including paediatric specialists in surgery and urology, imaging, pathology, psychology, nursing, and a neonatologist or an adolescent gynaecologist [63]. Communication with the family is generally led by 1 professional, supported by adequate intervention of the other members of the multidisciplinary team. Undertaking the diagnostic procedures described in this review requires that parents, or the patients if they have an age to understand, be comprehensively informed in advance so that they can participate in the decision of which tests to perform and when [2]. Although we have tried to provide typical diagnostic algorithms, it should be kept in mind that an individualized care plan is essential, considering the medical urgency for the diagnosis as well as the patients'/families' desire to proceed, which may vary according to their sociocultural background.

\section{Conclusion}

DSD may present with clinical and biochemical specificities according to the age at consultation. A detailed anatomic description of the external and internal genita- lia, after adequate imaging studies or surgical exploration, reproductive hormone-level assessment, and karyotyping generally give sufficient information for a primary diagnostic approach. More sophisticated technologies or invasive studies, such as mass spectrometry, cytogenomic microarray, next-generation sequencing, and histologic analysis help to reach an aetiologic diagnosis.

\section{Conflict of Interest Statement}

R.P.G. reports lecture honoraria from Novo Nordisk and Raffo, and travel grants from Merck, Novo Nordisk, Pfizer, and Sandoz. R.P.G. and R.A.R. have received honoraria from CONICET (Argentina) for technology services using the AMH ELISA until 2020. RAR received royalties derived from an agreement between INSERM (France) and Beckman-Coulter-Immunotech until 2020, for the development of an AMH ELISA kit, as well as lecture honoraria from Novo Nordisk and Sandoz, and travel grants from Biosidus, Merck, Novo Nordisk, Pfizer, and Sandoz.

\section{Funding Sources}

S.C. is recipient of a doctoral fellowship from CONICET (Argentina). This funding source had no role in the preparation of the manuscript.

\section{Author Contributions}

R.A.R. conceived the manuscript outline. R.P.G., S.C., and R.A.R. performed the data and bibliographic search. All authors discussed the contents, contributed to the manuscript writing, and approved the final version.

\section{References}

1 Barseghyan H, Délot EC, Vilain E. New technologies to uncover the molecular basis of disorders of sex development. Mol Cell Endocrinol. 2018;468:60-9.

2 Cools M, Nordenström A, Robeva R, Hall J, Westerveld P, Flück C, et al. Caring for individuals with a difference of sex development (DSD): a consensus statement. Nat Rev Endocrinol. 2018;14:415-29.

3 Flück C, Nordenström A, Ahmed SF, Ali SR, Berra M, Hall J, et al. Standardised data collection for clinical follow-up and assessment of outcomes in differences of sex development (DSD): recommendations from the COST action DSDnet. Eur J Endocrinol. 2019; 181:545-64.
4 Hughes LA, McKay-Bounford K, Webb EA, Dasani P, Clokie S, Chandran H, et al. Next generation sequencing (NGS) to improve the diagnosis and management of patients with disorders of sex development (DSD). Endocr Connect. 2019;8:100-10.

5 Grinspon RP, Bergadá I, Rey RA. Male hypogonadism and disorders of sex development. Front Endocrinol. 2020;11:211.

6 Lin YT, Capel B. Cell fate commitment during mammalian sex determination. Curr Opin Genet Dev. 2015;32:144-52.

7 Makela JA, Koskenniemi JJ, Virtanen HE, Toppari J. Testis development. Endocr Rev. 2019;40:857-905.
8 Josso N. Women in reproductive science: anti-mullerian hormone: a look back and ahead. Reproduction. 2019;158:F81-F89.

9 Shaw G, Renfree MB. Wolffian duct development. Sex Dev. 2014;8:273-80.

10 Flück CE, Pandey AV. Steroidogenesis of the testis: new genes and pathways. Ann Endocrinol. 2014;75:40-7.

11 Cunha GR, Vezina CM, Isaacson D, Ricke WA, Timms BG, Cao M, et al. Development of the human prostate. Differentiation. 2018; 103:24-45

12 Cunha GR, Baskin L. Development of human male and female urogenital tracts. Differentiation. 2018;103:1-4. 
13 Klonisch T, Fowler PA, Hombach-Klonisch S. Molecular and genetic regulation of testis descent and external genitalia development. Dev Biol. 2004;270:1-18.

14 Moses MM, Behringer RR. A gene regulatory network for Müllerian duct regression. Environ Epigenet. 2019;5:dvz017.

15 Bergadá I, Milani C, Bedecarrás P, Andreone L, Ropelato MG, Gottlieb S, et al. Time course of the serum gonadotropin surge, inhibins, and anti-Müllerian hormone in normal newborn males during the first month of life. J Clin Endocrinol Metab. 2006;91:4092-8.

16 Kuiri-Hänninen T, Seuri R, Tyrväinen E, Turpeinen U, Hämäläinen E, Stenman UH, et al. Increased activity of the hypothalamic-pituitary-testicular axis in infancy results in increased androgen action in premature boys. J Clin Endocrinol Metab. 2011;96:98-105.

17 Grinspon RP, Bedecarrás P, Ballerini MG, Iñiguez $\mathrm{G}$, Rocha $\mathrm{A}$, Mantovani Rodrigues Resende EA, et al. Early onset of primary hypogonadism revealed by serum anti-Müllerian hormone determination during infancy and childhood in trisomy 21. Int J Androl. 2011;34:e487-98.

18 Rey RA. The role of androgen signaling in male sexual development at puberty. Endocrinology. 2021;162(2):bqaa215.

19 Rey RA. Mini-puberty and true puberty: differences in testicular function. Ann Endocrinol. 2014;75:58-63.

20 Kuiri-Hänninen T, Sankilampi U, Dunkel L. Activation of the hypothalamic-pituitary-gonadal axis in infancy: minipuberty. Horm Res Paediatr. 2014;82:73-80.

21 Grinspon RP, Rey RA. When hormone defects cannot explain it: malformative disorders of sex development. Birth Defects Res C Embryo Today. 2014;102:359-73.

22 Rey RA, Grinspon RP. Normal male sexual differentiation and aetiology of disorders of sex development. Best Pract Res Clin Endocrinol Metab. 2011;25:221-38.

23 Hughes IA, Davies JD, Bunch TI, Pasterski V, Mastroyannopoulou K, MacDougall J. Androgen insensitivity syndrome. Lancet. 2012; 380:1419-28.

24 Picard JY, Cate RL, Racine C, Josso N. The persistent mullerian duct syndrome: an update based upon a personal experience of 157 cases. Sex Dev. 2017;11:109-25.

25 Prader A. Genital findings in the female pseudo-hermaphroditism of the congenital adrenogenital syndrome; morphology, frequency, development and heredity of the different genital forms. Helv Paediatr Acta. 1954;9: 231-48.

26 Ahmed SF, Khwaja O, Hughes IA. The role of a clinical score in the assessment of ambiguous genitalia. BJU Int. 2000;85:120-4.

27 van der Straaten S, Springer A, Zecic A, Hebenstreit D, Tonnhofer U, Gawlik A, et al. The external genitalia score (EGS): a European multicenter validation study. J Clin Endocrinol Metab. 2020;105.
28 Guercio G, Saraco N, Costanzo M, Marino R, Ramirez P, Berensztein E, et al. Estrogens in human male gonadotropin secretion and testicular physiology from infancy to late puberty. Front Endocrinol. 2020;11:72.

29 Bertalan R, Csabay L, Blazovics A, Rigo J Jr, Varga I, Halasz Z, et al. Maternal hyperandrogenism beginning from early pregnancy and progressing until delivery does not produce virilization of a female newborn. Gynecol Endocrinol. 2007;23:581-3.

30 Hoshino S, Obara K, Hoshii T, Kuroki H, Watanabe K, Tomita Y. Virilization of a female infant genitalia caused by a maternal androgen-producing adrenocortical tumor: a case report. Urol Case Rep. 2020;32:101253.

31 Grinspon RP, Rey RA. Molecular characterization of XX maleness. Int J Mol Sci. 2019;20: 6089.

32 Ahmed SF, Achermann JC, Arlt W, Balen A, Conway G, Edwards Z, et al. Society for endocrinology UK guidance on the initial evaluation of an infant or an adolescent with a suspected disorder of sex development (Revised 2015). Clin Endocrinol. 2016;84:771-88.

33 Lucas-Herald AK, Kyriakou A, Alimussina M, Guaragna-Filho G, Diver LA, McGowan $\mathrm{R}$, et al. Serum anti-Müllerian hormone in the prediction of response to hcg stimulation in children with DSD. J Clin Endocrinol Metab. 2020;105:1608-16.

34 Auchus RJ, Miller WL. Defects in androgen biosynthesis causing 46,XY disorders of sexual development. Semin Reprod Med. 2012;30: 417-26.

35 Dhayat NA, Dick B, Frey BM, d'Uscio CH, Vogt B, Flück CE. Androgen biosynthesis during minipuberty favors the backdoor pathway over the classic pathway: insights into enzyme activities and steroid fluxes in healthy infants during the first year of life from the urinary steroid metabolome. J Steroid Biochem Mol Biol. 2017;165:312-22.

36 Bertelloni S, Russo G, Baroncelli GI. Human chorionic gonadotropin test: old uncertainties, new perspectives, and value in $46, \mathrm{XY}$ disorders of sex development. Sex Dev. 2018;12: 41-9.

37 Mendonça BB, Gomes NL, Costa EM, Inacio M, Martin RM, Nishi MY, et al. 46, XY disorder of sex development (DSD) due to 17 betahydroxysteroid dehydrogenase type 3 deficiency. J Steroid Biochem Mol Biol. 2017;165: 79-85.

38 Miller WL. Mechanisms in endocrinology: rare defects in adrenal steroidogenesis. Eur $\mathrm{J}$ Endocrinol. 2018;179:R125-R41.

39 Kurnaz E, Kartal Baykan E, Türkyılmaz A, Yaralı O, Yavaş Abalı Z, Turan S, et al. Genotypic sex and severity of the disease determine the time of clinical presentation in steroid 17a-hydroxylase/17, 20-lyase deficiency. Horm Res Paediatr. 2020;93(9-10):558-66.
40 Dean B, Chrisp GL, Quartararo M, Maguire AM, Hameed S, King BR, et al. P450 oxidoreductase deficiency: a systematic review and meta-analysis of genotypes, phenotypes, and their relationships. J Clin Endocrinol Metab. 2020;105:dgz255.

41 Lutfallah C, Wang W, Mason JI, Chang YT, Haider A, Rich B, et al. Newly proposed hormonal criteria via genotypic proof for type II 3beta-hydroxysteroid dehydrogenase deficiency. J Clin Endocrinol Metab. 2002;87: 2611-22.

42 Güran T, Kara C, Yildiz M, Bitkin EC, Haklar G, Lin JC, et al. Revisiting Classical 3beta-hydroxysteroid dehydrogenase 2 deficiency: lessons from 31 pediatric cases. J Clin Endocrinol Metab. 2020:105.

43 Bouvattier C, Carel JC, Lecointre C, David A, Sultan C, Bertrand AM, et al. Postnatal changes of T, LH, and FSH in 46,XY infants with mutations in the AR gene. J Clin Endocrinol Metab. 2002;87:29-32.

44 Mendonça BB, Batista RL, Domenice S, Costa EM, Arnhold IJ, Russell DW, et al. Steroid $5 a$-reductase 2 deficiency. J Steroid Biochem Mol Biol. 2016;163:206-11.

45 Russell DW, Wilson JD. Steroid 5 alpha-reductase: two genes/two enzymes. Annu Rev Biochem. 1994;63:25-61.

46 Melo KF, Mendonça BB, Billerbeck AE, Costa EM, Inácio M, Silva FA, et al. Clinical, hormonal, behavioral, and genetic characteristics of androgen insensitivity syndrome in a Brazilian cohort: five novel mutations in the androgen receptor gene. J Clin Endocrinol Metab. 2003;88:3241-50.

47 Liu Q, Yin X, Li P. Clinical, hormonal and genetic characteristics of androgen insensitivity syndrome in 39 Chinese patients. Reprod Biol Endocrinol. 2020;18:34.

48 Chan AO, But BW, Lee CY, Lam YY, Ng KL, Tung JY, et al. Diagnosis of 5alpha-reductase 2 deficiency: is measurement of dihydrotestosterone essential? Clin Chem. 2013;59:798806

49 Flück CE, Meyer-Böni M, Pandey AV, Kempná P, Miller WL, Schoenle EJ, et al. Why boys will be boys: two pathways of fetal testicular androgen biosynthesis are needed for male sexual differentiation. Am J Hum Genet. 2011;89:201-18.

50 Rey RA, Belville C, Nihoul-Fékété C, MichelCalemard L, Forest MG, Lahlou N, et al. Evaluation of gonadal function in 107 intersex patients by means of serum antimüllerian hormone measurement. J Clin Endocrinol Metab. 1999;84:627-31.

51 Woelfle J, Hoepffner W, Sippell WG, Brämswig JH, Heidemann P, Deiss D, et al. Complete virilization in congenital adrenal hyperplasia: clinical course, medical management and disease-related complications. Clin Endocrinol. 2002;56:231-8.

52 Flück CE, Pandey AV. Human P450 oxidoreductase deficiency. Encyclopedia of Endocrine Diseases; 2019.
Clinical and Laboratory Workup in

Disorder of Sex Development
Horm Res Paediatr

DOI: $10.1159 / 000519895$ 
53 Grinspon RP, Loreti N, Braslavsky D, Valeri C, Schteingart H, Ballerini MG, et al. Spreading the clinical window for diagnosing fetalonset hypogonadism in boys. Front Endocrinol. 2014;5:51.

54 Pacenza N, Pasqualini T, Gottlieb S, Knoblovits P, Costanzo PR, Stewart Usher J, et al. Clinical presentation of Klinefelter's syndrome: differences according to age. Int J Endocrinol. 2012;2012:324835.

55 Bastida MG, Rey RA, Bergadá I, Bedecarrás P, Andreone L, del Rey G, et al. Establishment of testicular endocrine function impairment during childhood and puberty in boys with Klinefelter syndrome. Clin Endocrinol. 2007; 67:863-70.

56 Lunding SA, Aksglaede L, Anderson RA, Main KM, Juul A, Hagen CP, et al. AMH as predictor of premature ovarian insufficiency: a longitudinal study of 120 turner syndrome patients. J Clin Endocrinol Metab. 2015;100: E1030-8.

57 Kallio S, Aittomäki K, Piltonen T, Veijola R, Liakka A, Vaskivuo TE, et al. Anti-Mullerian hormone as a predictor of follicular reserve in ovarian insufficiency: special emphasis on FSH-resistant ovaries. Hum Reprod. 2012;27: 854-60.

58 Check JH, Cohen R, McCullen K, MitchellWilliams J. Sexual infantilism in a normal karotypic female related to ovarian agenesis associated with Müllerian agenesis: case report. Clin Exp Obstet Gynecol. 2015;42:5356.

59 Bry-Gauillard H, Larrat-Ledoux F, Levaillant JM, Massin N, Maione L, Beau I, et al. Antimullerian hormone and ovarian morphology in women with isolated hypogonadotropic hypogonadism/Kallmann syndrome. Effects of recombinant human FSH. J Clin Endocrinol Metab. 2017;102:1102-11.

60 Edelsztein NY, Racine C, di Clemente N, Schteingart HF, Rey RA. Androgens downregulate anti-Müllerian hormone promoter activity in the Sertoli cell through the androgen receptor and intact steroidogenic factor 1 sites. Biol Reprod. 2018;99:1303-12.

61 Valeri C, Lovaisa MM, Racine C, Edelsztein NY, Riggio M, Giulianelli S, et al. Molecular mechanisms underlying $\mathrm{AMH}$ elevation in hyperoestrogenic states in males. Sci Rep. 2020;10:15062.

62 Stuchi-Pérez EG, Hackel C, Oliveira LE, Ferraz LF, Oliveira LC, Nunes-Silva D, et al. Diagnosis of 5alpha-reductase type 2 deficiency: contribution of anti-Mullerian hormone evaluation. J Pediatr Endocrinol Metab. 2005;18: $1383-9$.

63 Ahmed SF, Achermann JC, Alderson J, Crouch NS, Elford S, Hughes IA, et al. Society for endocrinology UK guidance on the initial evaluation of a suspected difference or disorder of sex development (DSD) (revised 2021). Clin Endocrinol. 2021.

64 Aksglæde L, Sorensen K, Boas M, Mouritsen A, Hagen CP, Jensen RB, et al. Changes in anti-Mullerian hormone (AMH) throughout the life span: a population-based study of 1027 healthy males from birth (cord blood) to the age of 69 years. J Clin Endocrinol Metab. 2010;95:5357-64.

65 Kuijper EA, Ket JC, Caanen MR, Lambalk CB. Reproductive hormone concentrations in pregnancy and neonates: a systematic review. Reprod Biomed Online. 2013;27:33-63. 